\title{
Design de Sinalização para o Parque Estadual do Jaraguá
}

\author{
Signage Design for the Jaraguá State Park
}

\author{
CORDEIRO, João Pedro D.; Bacharel; Universidade Presbiteriana Mackenzie \\ joao.donn@gmail.com
}

OGASAWARA, Luís Alexandre F.; Me; Universidade Presbiteriana Mackenzie

luis.alexandre@mackenzie.br

\section{Resumo}

A vida nos grandes centros urbanos tem distanciado o Homem de seu habitat original: a natureza. Esta vem se tornando um sítio intangível, ao passo que é cada vez mais almejada como o último refúgio capaz de trazer conciliação e harmonia aos residentes das cidades, funcionando como um santuário. Todavia o modo de vida do Homem tem colocado em risco os ecossistemas do planeta de forma irremediável. O presente artigo, fruto do Trabalho de Conclusão de Curso apresentado para a obtenção do grau Bacharel em Design na Universidade Presbiteriana Mackenzie, busca evocar tais pontos colocando o projeto de Design de Sinalização para o Parque Estadual do Jaraguá, Unidade de Conservação que abriga um dos últimos remanescentes de Mata Atlântica na Região Metropolitana de São Paulo, como uma plataforma para o vínculo entre o Homem e a natureza.

Palavras-chave: Design; Sinalização; Parques; Parque Estadual do Jaraguá.

\begin{abstract}
Living in big urban centers has caused man to distance from your original environment: nature. Nature is becoming an intangible place, at the same time that is increasingly considered as the last refuge capable of bringing reconcilement to the city residents, functioning as a sanctuary. However, human's current way of life has put in irreparable danger the ecosystems of the planet. This article, product of the undergraduate thesis presented to obtain the bachelor degree in Design by Mackenzie Presbyterian University aims to evoke the points here presented by putting the project Signage Design for Jaraguá State Park, conservation unit which holds the remaining Atlantic Forest in the metropolitan area of São Paulo, as a platform for the link between man and nature.
\end{abstract}

Keywords: Design; Signage; Parks, Jaraguá State Park. 


\section{Introdução}

A vida nos grandes centros urbanos tem distanciado o Homem de seu habitat original: a natureza. Esta vem se tornando um sítio intangível, ao passo que é cada vez mais almejada como o último refúgio capaz de trazer conciliação e harmonia aos residentes das cidades, funcionando como um santuário. Certamente temos como retrato mais representativo deste santuário a figura da floresta.

Em diversas regiões, e principalmente entre os celtas, a floresta constituía um verdadeiro santuário em estado natural(...) No Japão, torii assinala não apenas a entrada do domínio de um templo, como também a de um verdadeiro santuário natural(...) Há uma estrita equivalência semântica, na época antiga, entre a floresta céltica e o santuário - nemeton. (CHEVALIER; GHEERBRANT, 2003, p.439).

Enquanto buscamos a natureza como retiro, alheios às consequências do modo de vida contemporâneo, demolimos ecossistemas inteiros de maneira irremediável. Segundo o INPE (Instituto Nacional de Pesquisas Espaciais), entre 2015 e 2016 foram desmatados 29.075 hectares (ha) do bioma Mata Atlântica nos 17 Estados do Brasil, em um aumento de 57,7\% em relação ao período de 2014 a 2015 (INPE, 2017, s/p). A devastação do "santuário" representa não só o fim de um reduto de placidez, mas põe em risco a própria sobrevivência da espécie humana.

O presente artigo busca apresentar como é possível, por meio do Design, suscitar este contato com o natural e promover a preservação do meio-ambiente. Trata-se de um projeto que apresenta um sistema voltado à Sinalização do Parque Estadual do Jaraguá. O Design de Sinalização pode ser definido como:

(...) uma associação de formas escultóricas informativas distribuídas num determinado espaço físico, aberto ou fechado. Suas características são a legibilidade e a veiculação de informações compreensíveis e fidedignas que antecipem as necessidades de esclarecimento dos usuários (CHAMMA; PASTOLETO, 2007, p.153).

A relevância deste projeto encontra lugar no fato de que parques públicos que perfazem áreas de conservação ambiental se encontram em situação de extrema decadência (Figura 1).

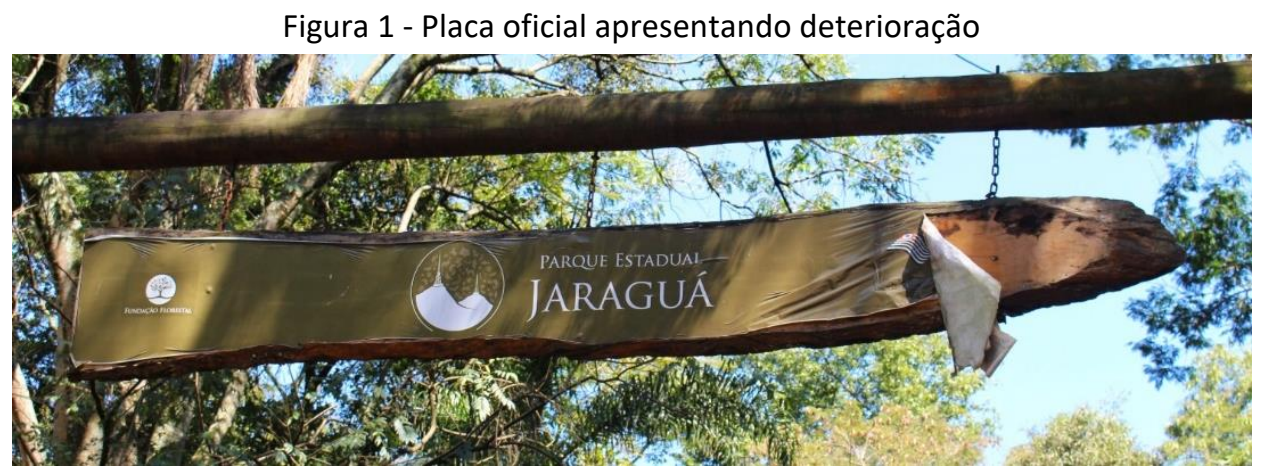

Fonte: fotografia elaborada pelo autor (2017)

Um projeto em Design de Sinalização prevê não apenas uma renovação estética do espaço, mas também busca atrair o público provocando uma experiência aprazível de conexão com a natureza (ou ainda o retorno ao "santuário"), aumentando o número de visitantes, para desta forma alavancar investimentos que proporcionem a contínua preservação do bioma em que o parque está situado. 


\section{Desenvolvimento}

\subsection{Design de Sinalização}

O design de sinalização está situado sob a grande área da comunicação visual, área essa que extrapola, estendendo-se para outros campos do conhecimento como a arquitetura, engenharia, psicologia, tecnologia de materiais, entre outras. De forma geral, pode-se definir a função principal do design de sinalização como a de "transmitir mensagens" (D'AGOSTINI; GOMES, 2010, p.115). Essas mensagens são intencionais e destinam-se à um usuário atendendo a um objetivo específico. Sobre o tema, Norberto Chamma e Pedro D. Pastolero apontam que o principal objetivo da sinalização é "informar os usuários não frequentes. Aqueles que não tem domínio do espaço/ambiente" (CHAMMA; PASTOLERO, 2007, p.158).

O design de sinalização tem como objetivo estudar os métodos, os processos e o conjunto de componentes que envolvem o projeto de comunicação para os espaços construídos, utilizando dados de pesquisas sobre o ambiente, o usuário, a forma e a informação. É uma disciplina fundada sobre os pilares da área de projeto e, em virtude disso, precisa acompanhar a evolução de métodos de trabalho, os processos tecnológicos, bem como as modificações na relação entre a comunicação dos ambientes com seus usuários (D'AGOSTINI, 2017, p.26).

Existem importantes associações ao redor do mundo cujo trabalho está voltado para o estudo e desenvolvimento de projetos em Design de Sinalização, estas são: SEGD (Society for Environment Graphic Design) nos Estados Unidos, SDS (Sign Design Society) em Londres, SDA (Japan Sign Design Association) no Japão e no Brasil a ABSA (Associação Brasileira de Sinalização Ambiental), entre outras.

\subsection{O Parque Estadual do Jaraguá}

Uma das importantes Unidades de Conservação na cidade de São Paulo, que faz parte da Reserva da Biosfera declarada pela UNESCO (Organização das Nações Unidas para a Educação, a Ciência e a Cultura), é o Parque Estadual do Jaraguá (PEJ), localizado na região Noroeste da cidade. Segundo o Plano de Manejo:

O Parque Estadual do Jaraguá se configura como uma UC (Unidade de Conservação) de alta relevância para a região metropolitana, pois além de minimizar o impacto urbano ambiental provocado pelos setores urbano e industrial, também, contribui diretamente para o sistema de unidades de conservação da região metropolitana e para o sistema de áreas verdes do município de São Paulo (GOVERNO DO ESTADO DE SÃO PAULO, 2010, p.6).

Uma Unidade de Conservação consiste em uma área conservação ambiental que está sob o gerência do poder público. Além do PEJ, há outras 49 Unidades de Conservação que são administradas pela Fundação Florestal que está associada à Secretaria do Meio Ambiente. Segundo o Plano de Manejo:

(...) o Jaraguá se configura num fragmento de grande importância para as espécies que se encontram em seu interior, isoladas de outros ambientes naturais. Ao mesmo tempo configura-se como um espaço privilegiado e uma das poucas alternativas na metrópole para educação ambiental e recreação em ambiente preservado (GOVERNO DO ESTADO DE SÃO PAULO, 2010, p.36).

A região é um dos últimos remanescentes da Mata Atlântica na cidade e foi declarada por meio do Decreto ${ }^{\circ} 38.391$ como Parque Estadual em 1961 com o objetivo de proteger os recursos naturais, além de incentivar a pesquisa e a educação ambiental. Como está descrito no Plano de 
Manejo, possui uma área total de 492,68 hectares (GOVERNO DO ESTADO DE SÃO PAULO, 2010, p.29). Parte do parque está situado no ponto mais alto de São Paulo. O Pico do Jaraguá soma $1.135 \mathrm{~m}$ de altitude, que permite uma vista generosa da cidade de São Paulo.

Somados os fatores histórico-culturais com as características naturais, o Parque Estadual do Jaraguá se apresenta como uma forte opção ao turismo e ao lazer. Ele conforma em si um dos últimos "santuários" naturais presentes na cidade de São Paulo, uma chance de retiro ao Homem da cidade, de reencontro com o primordial, e por isso foi escolhido como local para o projeto.

\subsection{Metodologia}

A metodologia para a elaboração do projeto está pautada nos quatro fatores projetuais essenciais que devem serem articulados em um trabalho de sinalização segundo Douglas D'Agostini. Estes são "o usuário, o ambiente, a forma e a informação" (D'AGOSTINI, 2017, p.26), a fim de proporcionar a melhor relação entre o usuário e o espaço construído.

\subsubsection{Análise e Classificação do Ambiente}

A primeira parte da análise do ambiente é uma observação crítica a respeito das problemáticas encontradas no espaço. Deterioração: as placas do parque se encontram em estado de deterioração devido às intempéries. Problema de identidade: no parque, existem dois modelos de placas de sinalização: modelo antigo e modelo atual (Figura 2). Ambos coexistem e competem no sistema do parque, criando um problema de identidade.

Figura 2 - Modelo antigo (à esquerda) e modelo atual (à direita) de placa

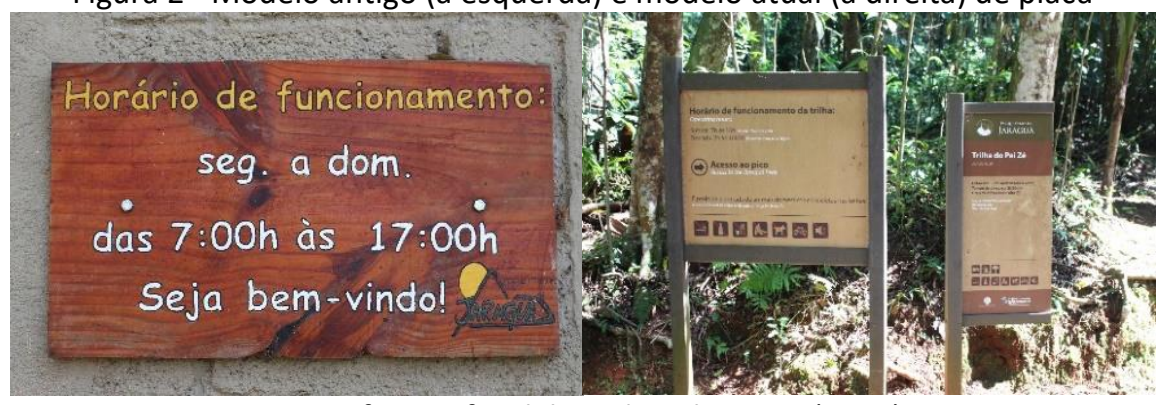

Fonte: fotografia elaborada pelo autor (2017)

O ambiente do parque foi classificado segundo os critérios levantados por Douglas D'Agostini e Luís Antônio V. N. Gomes no livro Design de Sinalização: planejamento, projeto e desenho (2010). A ferramenta serve para delimitar as soluções do projeto, a fim de excluir propostas que estejam fora do escopo.

1. Público: o Parque Estadual do Jaraguá é um ambiente público, sem restrições de acessos dos usuários. Esta informação serve para delimitar possíveis mensagens proibitivas que o local possa haver. Alguns locais exigem que o indivíduo se identifique antes do acesso.

2. Quilo Habitat: diz respeito a quantidade de pessoas que transitam no local (milhares de pessoas). Grande extensão sem estrutura complexa.

3. Permanente: as estruturas do Parque Estadual do Jaraguá são permanentes. Essa observação permite delimitar escolha de materiais que atendam a requisitos de durabilidade, por exemplo. 
4. Aberto: o Parque Estadual do Jaraguá é um ambiente aberto. Essa observação permite delimitar escolha de materiais que atendam a requisitos de durabilidade e resistência às intempéries, e também de leitura devido à influência da luz natural.

5. Circulação: o ambiente é majoritariamente de circulação. Isso significa que grande parte da leitura das informações será feita pelo usuário em movimento.

6. Plano único: o Parque Estadual do Jaraguá possui um único plano de interação. Essa observação delimita soluções de hierarquia de informações, a fim de proporcionar o melhor deslocamento dos usuários.

\subsubsection{Os Usuários}

Para entender as principais demandas dos usuários do Parque Estadual do Jaraguá, foi realizada uma pesquisa in loco com 50 visitantes. $O$ proposta do questionário foi obter insumos por meio de perguntas indiretas. Em vez de questionar a respeito da qualidade da sinalização, por exemplo, optou-se por entender se o usuário conhecia ou não determinada trilha ou se já havia se perdido durante a visita. Abaixo os resultados mais interessantes da pesquisa realizada (Figura 3).

Figura 3 - Resultados de Pesquisa: questões 2, 3, 4 e 5.

2. Você já se perdeu no Parque Estadual do Jaraguá?

Sim Não

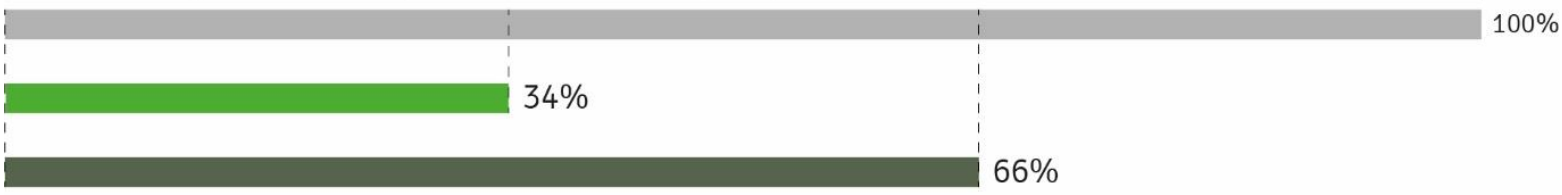

3. Quais trilhas você conhece?

Pai Zé $\square$ Lago Bica Nenhuma Silêncio

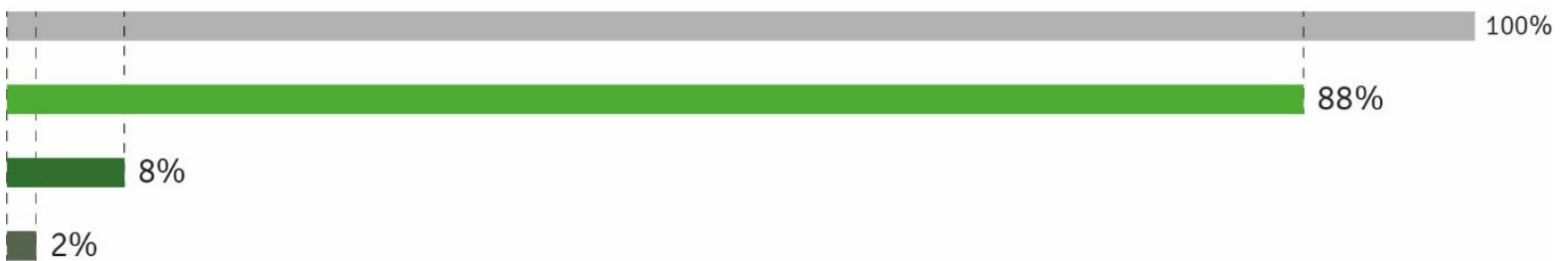

Fauna e Flora $\square$ História

4. Sobre o PEJ, você gostaria de conhecer mais:

Trilhas e Percursos —Curiosidades

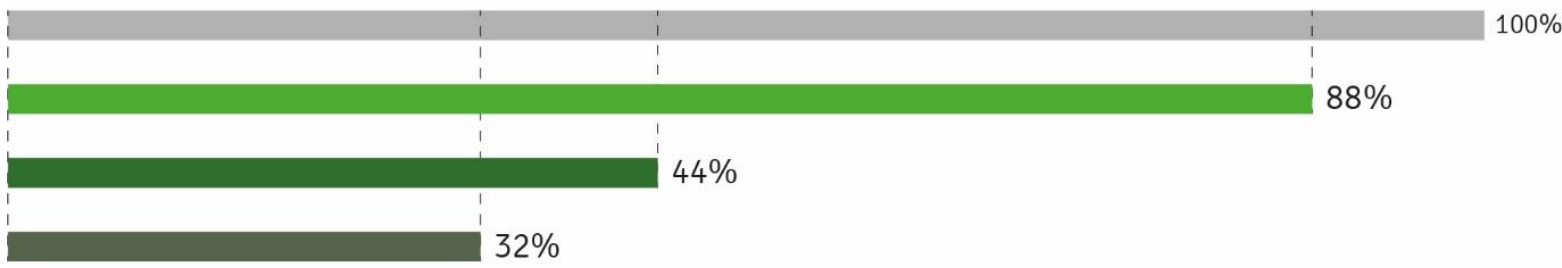

Trilhas —Churrasqueiras

5. Quando vem ao parque, você costuma utilizar: __ Área para pic-nic Q Quadras e Playgrounds

\section{$32 \%$}

Fonte: elaborado pelo autor (2017) 
Os dados revelam que a sinalização atual consegue suprir, de forma geral, as necessidades dos usuários e que as trilhas do parque são pouco conhecidas. A Trilha do Pai Zé possui o maior número pois é a única que leva ao Pico do Jaraguá, principal atrativo do local. O resultado mostra que é preciso aumentar a informação sobre as trilhas.

Com efeito, a pesquisa mostra que as informações mais requeridas pelos usuários são a respeito da fauna, flora, trilhas e percursos do parque. O projeto deve levar estes pontos em consideração. Além disso, as trilhas são de fato o maior atrativo do parque (item 5). Unindo essa informação com aquela obtida no item 4, temos que destacar a relevância das trilhas e percursos como motor das visitas no parque.

\subsubsection{A Informação}

Entende-se como parte essencial do projeto o estudo da organização do espaço. Primeiramente buscou-se observar as trilhas, os programas de lazer (churrasqueiras e playgrounds), acessos e programas de infraestrutura (pontos de informação e banheiros) do Parque Estadual do Jaraguá.

As trilhas são um forte atrativo de lazer do parque. Sinalizar o começo e o fim de cada uma delas é essencial não só no que diz respeito à localizar o usuário no espaço, mas também atende a questões de segurança impedido que alguém possa ultrapassar os limites da trilha. Os acessos devem conter todas as informações do parque, a fim de o usuário sobre as possibilidades de uso do local. Em seguida, observou-se os principais atrativos do parque e estruturas físicas. Esta análise serviu para relacionar possíveis pontos que necessitam de sinalização e que tipo de mensagem distribuir dentro do sistema.

\subsubsection{A Forma}

\subsection{Construção dos Layouts das Placas}

Abaixo, pode-se observar os roughs iniciais (Figura 4) para a construção dos layouts das placas. Os desenhos fornecem uma orientação formal para a construção do sistema.

Figura 4 - roughs iniciais

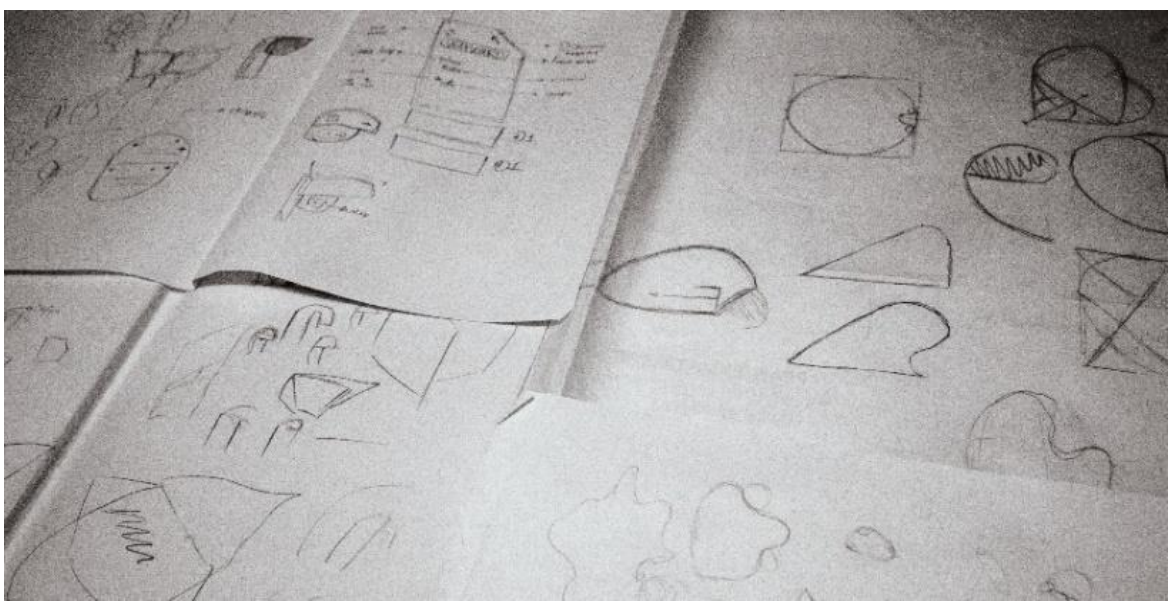

Fonte: elaborado pelo autor (2017) 


\subsubsection{Exercício Formal I}

Sabe-se que não existem formas completamente retas na natureza. Esse fato orientou o desenvolvimento do Exercício Formal I. O critério utilizado foi o de formas circulares e eixo birradial para a construção de formas (Figura 5) que pudessem servir como suporte do sistema de sinalização e que pudessem ser associadas a ideia de natureza e suas características particulares.

Figura 5 - construção de formas usando eixos birradiais
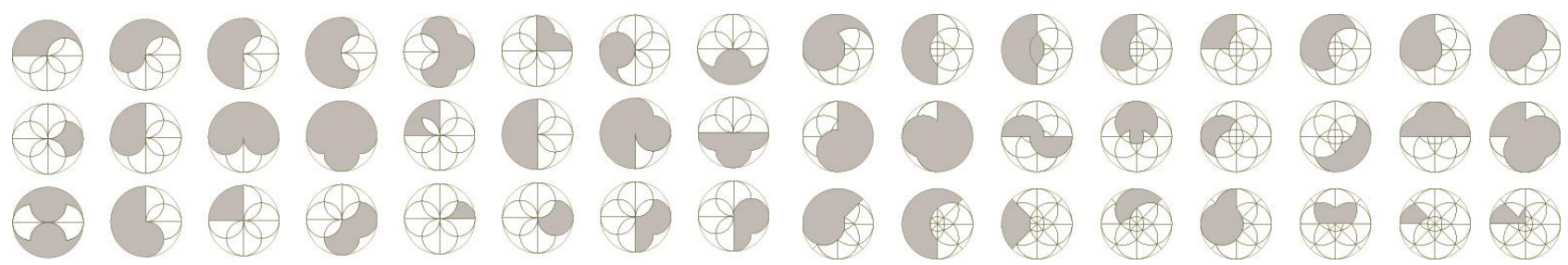

Fonte: elaborado pelo autor (2017)

\subsubsection{Exercício Formal II}

O fato de não existirem formas absolutamente retas na natureza também orientou o desenvolvimento do Exercício Formal II. Além disso, a proposta foi buscar o padrão intrínseco à natureza, ou a sua lógica oculta. Desta forma, o Exercício Formal II leva em conta a construção de modelos a partir do Retângulo e Ouro e da Espiral Áurea (Figura 6). Este critério considera a referência à natureza e a busca de uma composição harmônica do sistema de sinalização.

Figura 6 - construção de modelos partir do Retângulo e Ouro e da Espiral Áurea
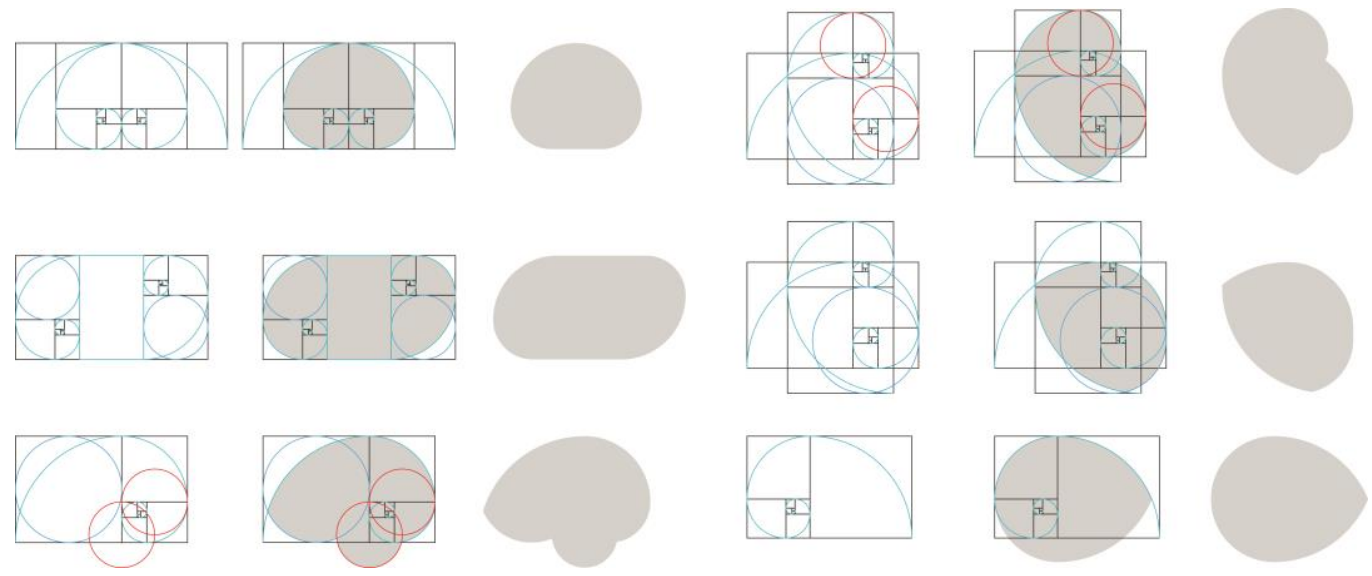

Fonte: elaborado pelo autor (2017)

\subsection{Elementos do Sistema}

\subsubsection{Código Tipográfico}

A tipografia para o sistema de sinalização deve, em primeiro lugar, atender a critérios de legibilidade. Além disso, deve apresentar uma coerência formal com o sistema de placas. Neste sentido, a família tipográfica escolhida é a Signika, desenvolvida especialmente para wayfinding, sinalização e demais peças onde há a necessidade de clareza de informações. Além disso, o desenho das letras é assimétrico e elegante, características que ajudaram na escolha desta para o 
desenvolvimento do sistema. A família foi elaborada pela designer polonesa Anna Giedryś e é gratuita (OpenType), possuindo também um ajuste ótico para texto em negativo.

No livro Design de Sinalização (2017), Douglas D'Agostini estabelece o tamanho em centímetros do caractere tipográfico para leitura à distância. Segundo o autor "essa avaliação é estritamente ergonômica pois trata do conforto que os usuários terão ao visualizar a informação" (D'AGOSTINI, 2017, p.336). Abaixo o padrão estabelecido por D'Agostini e a aplicação na tipografia Signika, juntamente com a especificação do tamanho do tipo em pontos (Figura 7).

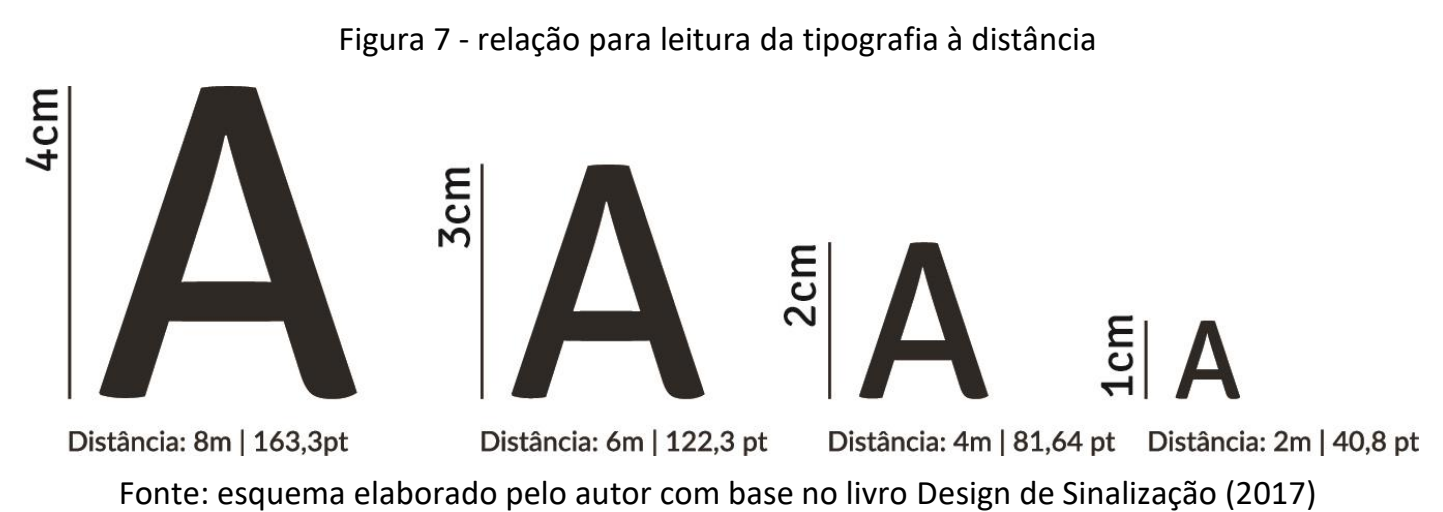

\subsubsection{Código Cromático}

As cores do sistema (Figura 8) foram escolhidas a partir de critérios de legibilidade. A luz natural é uma problemática a ser resolvida em projetos de sinalização para parques. Além disso, é importante que as cores não venham a chamar mais atenção que a própria natureza.

\section{Jaraguá}

Figura 8 - Código Cromático

PANTONE 7406 C

Para utilização em placas (detalhe do contraste com a tipografia)

\section{Jaraguá}

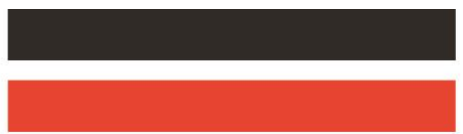

PANTONE NEUTRAL BLACK C

Para tipografia - texto, pictogramas e detalhes

PANTONE BRIGHT RED C

Para pictogramas e detalhes proibitivos

PANTONE 389 C

Para utilização em placas (detalhe do contraste com a tipografia)

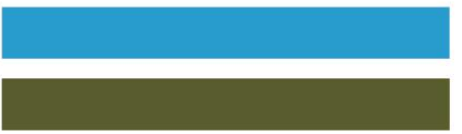

PANTONE 2995 C

Para detalhes em mapas

PANTONE $317 \mathrm{C}$

Para detalhes em mapas

Fonte: elaborado pelo autor (2017)

\subsubsection{Código Pictográfico}

A fim de manter a coerência formal do sistema, o código pictográfico foi elaborado utilizando-se da mesma ferramenta vista no Exercício Formal II, que leva em conta a construção de modelos a partir do Retângulo e Ouro e da Espiral Áurea. Este critério considera a referência à natureza e a busca de uma composição harmônica do sistema de sinalização, em concordância com os modelos das placas. A seguir o exemplo de composição dos pictogramas (Figura 9) e o panorama do código desenvolvido para Permissões e Pontos Importantes (Figura 10). 
Figura 9 - Exemplo de composição dos pictogramas

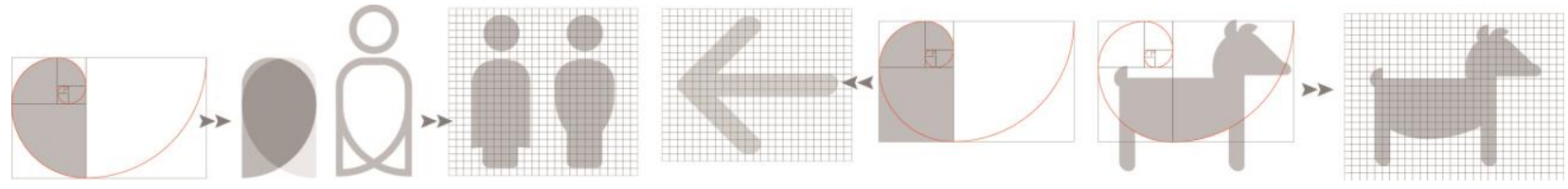

Fonte: elaborado pelo autor (2017)

Figura 10 - Pictogramas de Permissões e Pontos Importantes

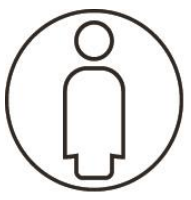

Feminino

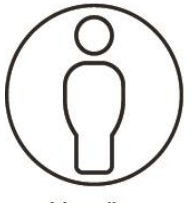

Masculino

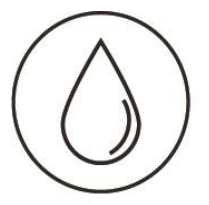

Água

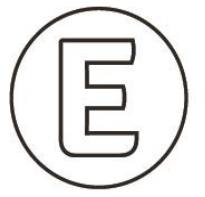

Permitido Estacionar

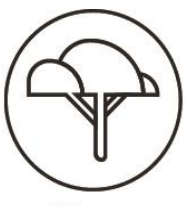

Natureza

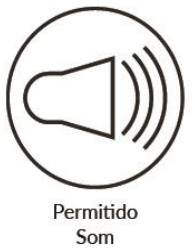

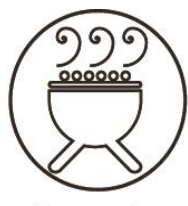

Churrasqueiras

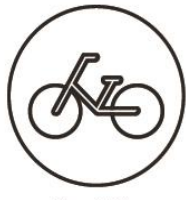

Permitido Bicicleta

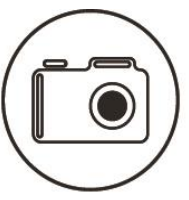

Permitido

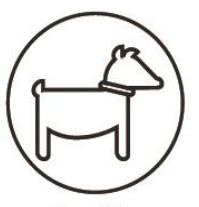

Permitido Animais

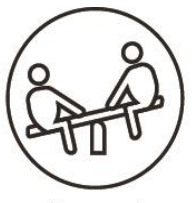

Playground

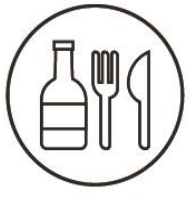

Permitido

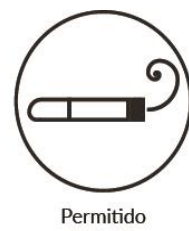

Permitido

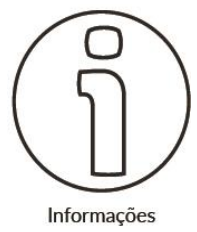

Fonte: elaborado pelo autor (2017)

\section{Resultados}

\subsection{Detalhamento do Sistema}

Abaixo, pode-se observar o conjunto de modelos de placas componentes do sistema de sinalização para o Parque Estadual do Jaraguá (Figura 11). Cada modelo atende à uma função específica de acordo com as necessidades dos usuários no espaço.

Figura 11 - Conjunto de modelos de placas componentes do sistema de sinalização.

Da esquerda para a direita: Modelo A, B, C D e E
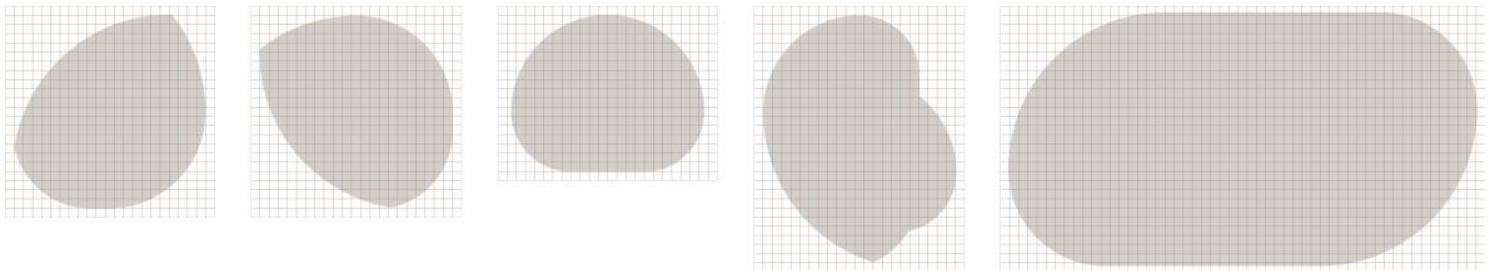

Fonte: elaborado pelo autor (2017)

Cada um dos modelos possui uma característica, que determina sua função dentro do sistema de sinalização: Modelo A: Explicativas e Orientação; Modelo B: Localização e Orientação; Modelo C: Infraestruturas e Botânica; Modelo D: Situação; Modelo E: Principais (Explicativas). Sistema e Relações de Proporção.

Abaixo (Figura 12), pode-se observar as relações de proporção entre os componentes do sistema em relação aos usuários (considerando uma média de altura do brasileiro: 1,70m). 
Figura 12 - Relações de proporção

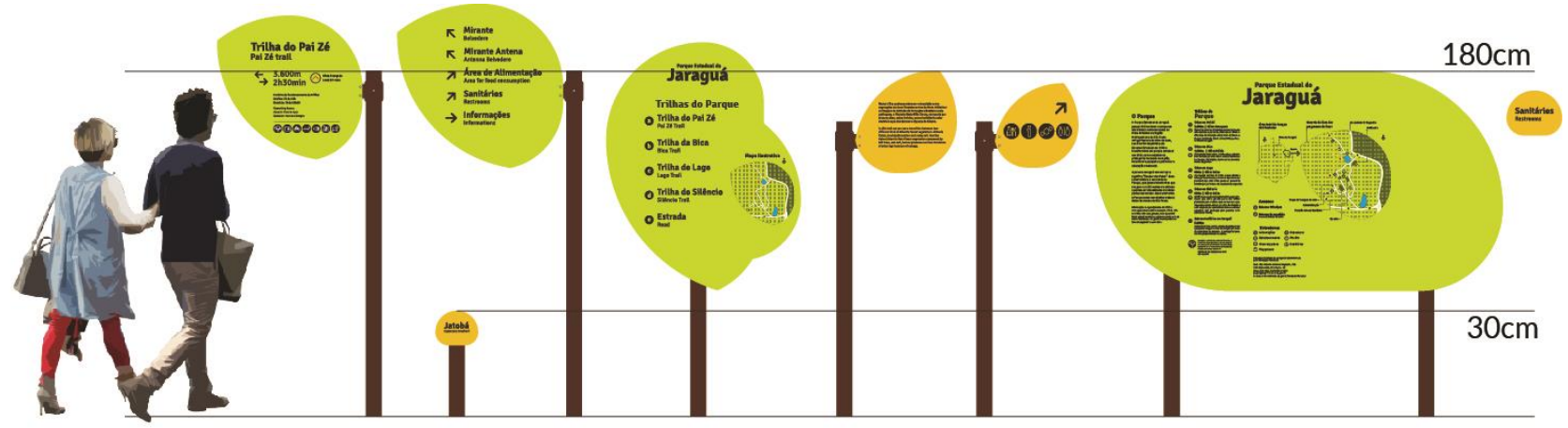

Fonte: elaborado pelo autor (2017)

\subsubsection{Código Normativo}

Pensando em otimizar a organização, distribuição e implantação do sistema, foi criado um código normativo onde as siglas estão relacionadas ao tipo de atributo da mensagem (ex: PE - Placa Explicativa) e os números determinam o modelo específico a ser aplicado no parque.

Código: (PE) Placas Explicativas; (POP) Placa de Orientação de Pictogramas; (PL) Placa de Localização; (PO) Placa de Orientação; (PIN) Placa de Infraestrutura; (PB) Placa Botânica; (PS) Placa de Situação; (PP) Placa Principal.

Como foi colocado anteriormente, a sigla define o modelo e a função do elemento, e o número é a base que determina a informação em relação ao local de colocação da placa. Por exemplo: PL001 = Placa de Localização 001 (placa para o início Trilha do Pai Zé).

A seguir os modelos para apreciação: PL001, PO001, PIN001 e PBO001 (Figura 13); PS001, PIN001-A (Figura 14).

Figura 13 - Da direita para a esquerda: PL001, P0001, PIN001 e PBO001
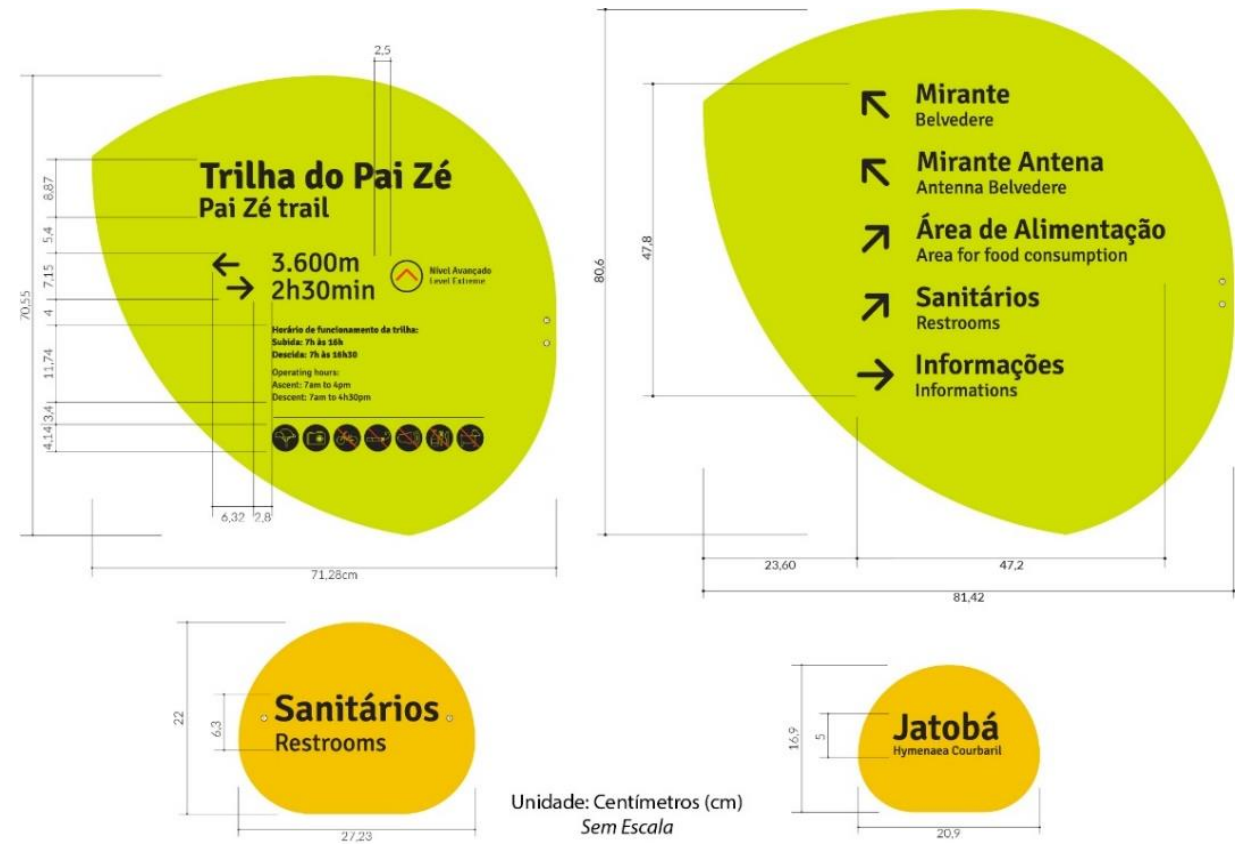

Fonte: elaborado pelo autor (2017) 


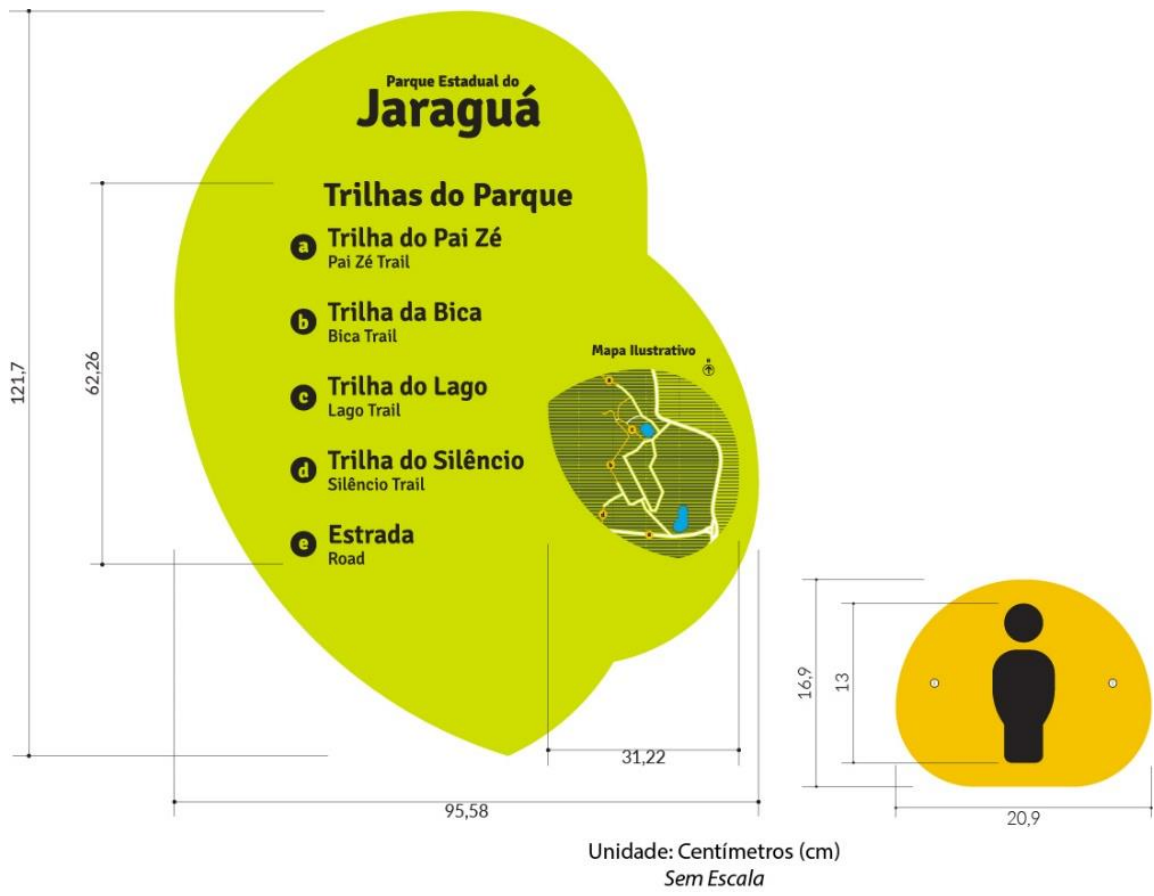

Fonte: elaborado pelo autor (2017)

\subsubsection{Materiais e Processos de Fabricação}

Pensando em durabilidade para resistência às intempéries, visando o maior tempo de uso das placas, optou-se por utilizar chapas de aço galvanizado. A gravação é feita em baixo relevo, e o suporte também é em aço galvanizado com pintura epóxi eletrostática. Todos os elementos foram pensados para durarem o máximo possível dentro do ambiente do parque.

Para o suporte da sinalização a solução proposta é clássica. O suporte tem uma seção oblonga ( $77 \times 40 \times 2,65 \mathrm{~mm}$ ), luvas para o encaixe das placas e é revestido com pintura epóxi eletrostática (PANTONE 4625C).

\subsubsection{Material Gráfico}

Pensando em melhorar a experiência dos usuários no parque, foi produzido um material gráfico (folder) de medidas 39,6 × 23cm (aberto) e 9,9x 23 (fechado). O material deverá ser impresso em impressão $4 \times 4$ e papel couchê $180 \mathrm{~g}$. Ele contém um mapa ilustrativo (Figura 15) e informações essenciais a respeito do parque (Figura 16). 
Figura 15 - Folder aberto (parte interna)

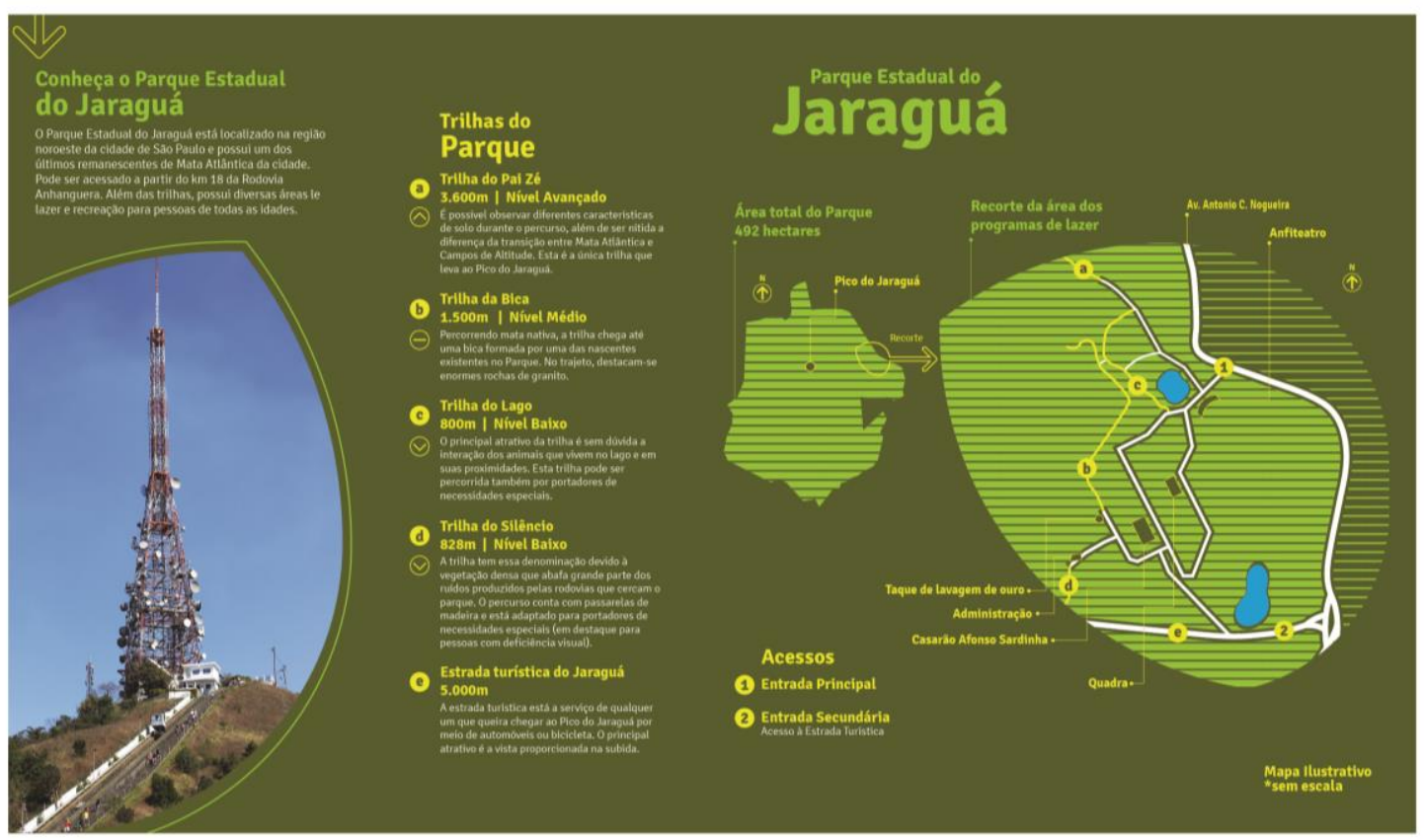

Fonte: elaborado pelo autor (2017)

Figura 16 - Folder aberto (parte externa)
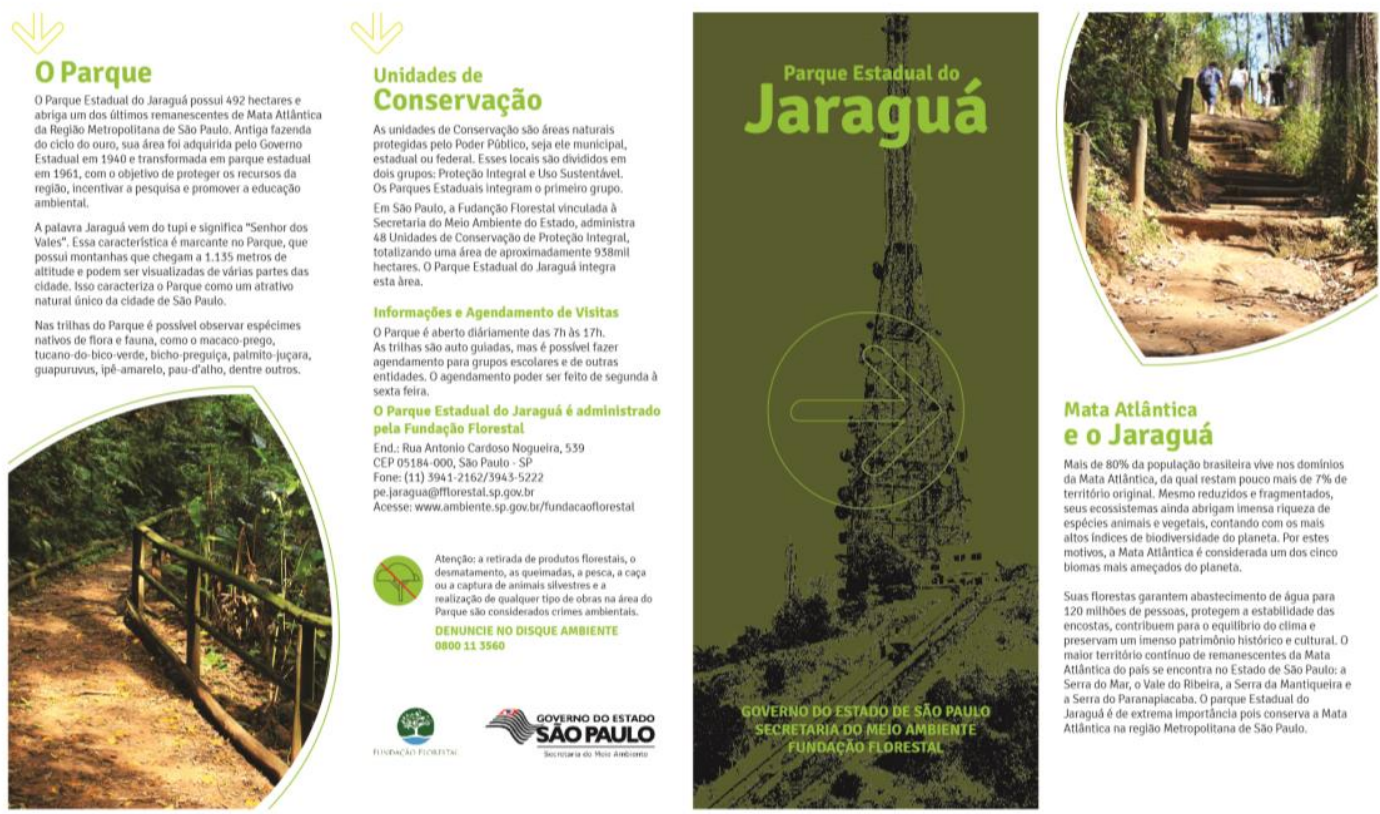

Mata Atlântica

e o Jaraguá

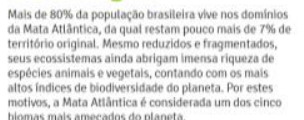

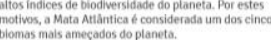

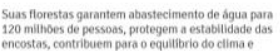

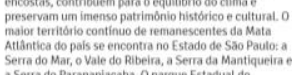

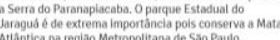

Fonte: elaborado pelo autor (2017)

\section{Considerações Finais}

A área do Design de Sinalização é completa em termos projeto porque articula o desenvolvimento uma série de conhecimentos diversos que transitam entre o Desenho Industrial, a Programação Visual e os Sistemas de Informações. Em suma, o Design de Sinalização é uma orquestra de muitas frentes. 
Por isso no mercado, para este tipo de projeto, entende-se que o processo projetual dure em média três anos. O projeto aqui apresentado foi elaborado em um tempo muito menor, mas não com menos aprofundamento dos métodos para a produção de um sistema de sinalização coerente. Os modelos mais clássicos de sinalização levam em conta a modularidade de formas quadradas e retangulares. Neste sentido, o objeto proposto neste projeto vai além do usual e coloca um posicionamento em prol da semântica dos elementos.

Projetos que visam a proteção do meio ambiente vem ganhando ênfase no mercado de Design. Para o Parque Estadual do Jaraguá há quem diga que, por se tratar de uma Unidade de Conservação, o perigo da devastação é algo a ser desconsiderado. Mas a ameaça da especulação imobiliária é real dentro da perspectiva de grandes cidades como São Paulo.

O projeto apresentado vem de encontro a essa problemática no sentido de aumentar o número de visitantes no parque, de forma a alavancar investimentos que auxiliem na preservação do bioma Mata Atlântica. Além disso, o projeto prevê a aproximação do Homem com a natureza. Em outras palavras, a preservação do "santuário" indispensável ao Homem por meio da comunhão com o primordial.

\section{Referências Bibliográficas}

CHAMMA, Norberto; PASTOLERO, Pedro D. Marcas e Sinalização: práticas em design corporativo. São Paulo: Senac, 2008.

CHEVALIER, Jean; GHEERBRANT, Alain. O Dicionário de Símbolos. Rio de Janeiro: Editora José Olympio Ltda, 2013.

D'AGOSTINI, Douglas. Design de Sinalização. São Paulo: Blucher, 2017.

D'AGOSTINI, Doulgas; GOMES, Luis Antonio V.N. Design de Sinalização: planejamento, projeto e desenho. Porto Alegre: Editora UniRitter, 2010.

GOVERNO DO ESTADO DE SAO PAULO. Plano de Manejo do Parque Estadual do Jaraguá. Disponível em: <http://arquivos.ambiente.sp.gov.br/fundacaoflorestal/2012/01/PE_\%20JARAGUA/Volume_ Principal_completo.pdf> Acesso em: 13 de out. 2017.

INPE. Desmatamento da Mata Atlântica cresce quase $60 \%$ em um ano. Disponível em: <http://www.inpe.br/noticias/noticia.php?Cod_Noticia=4471> Acesso em: 11 de set. 2017. 